\title{
Yatay Toprak Isı Değiş̧iricilerdeki Basınç Kayıplarının İki Boyutlu Bilgisayar Simülasyonları ile Enerji Verimliliği Bakımından Değerlendirilmesi
}

\author{
Azam AMETİ, Adil DEĞİRMENCİ, Mehmet Ekrem ÇAKMAK* \\ Yalova Üniversitesi, Mühendislik Fakültesi, Enerji Sistemleri Mühendisliği Bölümü, Yalova \\ (ORCID: 0000-0002-2854-3141) (ORCID: 0000-0002-9037-6428) (ORCID: 0000-0002-4073-096X)
}

\begin{abstract}
$\ddot{O} \mathbf{z}$
$\mathrm{Bu}$ çalışmada yedi farklı geometrik tasarıma sahip yatay toprak 1sı değiştiricilerin enerji verimini etkileyen basınç kayıpları bilgisayar destekli simülasyonlar aracıllğı ile incelenmiştir. $30 \mathrm{~m}^{2}$ 'lik $(6 \mathrm{mx} 5 \mathrm{~m})$ bir bahçe alanında kullanılmak üzere tasarlanan modeller, denklemlerin hesaplama kolaylığı açısından, iki boyutlu olarak oluşturulmuştur. Her bir tasarım ısı değişim yüzey alanları, basınç kayıpları ve enerji verimlilikleri açısından karşılaştırılmış̦tır. Enerji verimlilikleri açıssından karşılaştırılmaları ısı değişim yüzey alanlarının basınç kayıplarına oranı olarak tabir edilen enerji kazanım oranı değerleri üzerinden yapılmıştır. Elde edilen sonuçlara bakıldığında Tasarım-6'nın en yüksek 1sı değişim yüzey alanına $\left(6,9681 \mathrm{~m}^{2}\right)$, en düşük basınç kaybına $(88,9790 \mathrm{kPa})$ ve aynı zamanda en yüksek enerji kazanım oranına sahip olduğu $\left(0,0783 \mathrm{~m}^{2} \mathrm{kPa}^{-1}\right)$ görülmüştür. Her ne kadar diğer tasarımlara göre Tasarım-6 en enerji verimli gözükse de işletim ve bakım açısından değerlendirildiklerinde diğer tasarımlar yek pare olarak kullanılabileceklerken Tasarım-6'nın çok fazla bağlantı elemanı içermesinden dolayı pratik kullanımının riskli olduğu düşünülmektedir. Sonuçların projenin geliştirilmeye devam edilmesi açısından çok verimli olduğu görülmüştür.
\end{abstract}

Anahtar kelimeler: Enerji verimliliği, basınç kaybı, modelleme, benzetim, toprak 1sı değiştirici

\section{Energy Efficiency Assessment of Pressure Losses in Horizontal Ground Heat Exchangers with Two-Dimensional Computational Simulations}

\begin{abstract}
In this study horizontal ground heat exchangers with seven different geometric patterns were investigated for their energy efficiencies using computational simulations. The geometric patterns were designed to fit in a garden area of $30 \mathrm{~m}^{2}(6 \mathrm{mx} 5 \mathrm{~m})$ and the models were constructed two-dimensionally for the ease of computational calculations. The designs were compared to each other in terms of heat exchange surface areas, pressure losses, and energy efficiencies. To better facilitate the energy efficiency comparison of the designs the energy gains ratio (EGR) was used. It was described as the ratio of heat exchange surface area to pressure loss. The results showed that the Design-6 had the highest heat exchange surface area $\left(6.9681 \mathrm{~m}^{2}\right)$, the lowest pressure loss $(88.9790 \mathrm{kPa})$, as well as the highest EGR value of $0.0783 \mathrm{~m}^{2} \mathrm{kPa}^{-1}$. However, since the Design-6 was designed to have too many pipe joints, whereas the other designs might be used as intact pipeline, the practical use of the Design- 6 was thought to be risky from the operational maintenance point of view. The results were promising to help improving the project.
\end{abstract}

Keywords: Energy efficiency, pressure loss, modeling, simulation, ground heat exchanger

\section{Giriş}

Dünya genelinde ülkelerin enerji ithalatlarını düşürmek için başvurdukları en vaat edici yöntem enerji verimliliğidir [1-3]. Bu bakımdan enerji verimliliği bir nevi enerji kaynağı olarak kabul edilebilir. Dünya genelinde evsel enerji tüketiminin, özellikle kış aylarında, ısıtma kaynaklı olduğu hesaplanmaktadır. Kış

"Sorumlu yazar: mehmet.cakmak@yalova.edu.tr

Geliş Tarihi: 28.03.2021, Kabul Tarihi:12.08.2021 
aylarında 1sıtma verimliliğini artırmak için önerilen önemli sistemlerden biri de toprak kaynaklı 1S1 pompalarıdır [4-7].

$\mathrm{Bu}$ sistemler sayesinde toprak yüzeyine ulaşan güneş ışınlarının toprağa aktardığı termal enerji, toprağın içinde hapsolmak yerine, ekonomik kullanımına sunulabilmektedir. Toprak kaynaklı 1s1 pompaları hakkında yapılan çalışmalar gün geçtikçe artmaktadır ama yaygın kullanımlarının sağlanması halen tam olarak sağlanamamıştır. Yaygın kullanımın sağlanması önündeki en büyük sınırlama bu sistemlerin kullanılacakları yere göre özel olarak tasarlanmaları gerekliliğidir. Tasarımı en çok zorlayan nokta ise 1S1 pompasının ana elemanı olan ve enerjiyi topraktan alabilmesini sağlayan is1 değiştiricilerinin seçimidir [4-11]. Toprak 1sı değiştiricilerin seçimi kurulacakları alanın büyüklüğüne, iklim şartlarına ve toprağın özelliklerine bağlı olarak değişmektedir. Emsalleri arasından kurulum maliyetinin düşük olması açısından yaygın kullanıma en uygun olduğu düşünülen yatay-sığ serimli toprak 1sı değiştiricilerdir. Ama halen bu tip 1sı değiştiricilerin kullanılacakları bölge iklimine ve uygulama alanının büyüklüğüne uygun olarak tasarlanabilmeleri için pratik yöntemler geliştirmeye çalışılmaktadır [4-11]. Geleneksel tasarım yöntemi olan deneysel inceleme (pilot ölçekli deneysel tasarım gibi) hem maliyetli hem de uzun zaman almaktadır. Deneysel tasarım yöntemlerine alternatif olarak, özellikle son yirmi yıllık süre içerisinde bilgisayar teknolojisindeki hızlı gelişime bağlı olarak, bilgisayar destekli simülasyonlar toprak 1sı değiştiricilerin tasarımı sürecinde en çok tercih edilmeye başlanan bir yöntem olmuştur [8-11]. Ama maalesef tasarım açısından son kullanıcı olarak kabul edebileceğimiz perakende satıcının sistemin kurulacağı yere özgü 1sı değiştirici tasarım yapabilmesi için bilgisayar destekli simülasyonların pratik kullanımları hakkında yeterli çalışma yoktur [8-11, 14-17].

Yatay-sarmal tip toprak 1sı değiştirici tasarımında dikkat edilecek iki nokta vardır; birincisi 1sı değiştirici içerisindeki taşıyıcı akışkanın hareketi için gerekli pompalama gücü, ikincisi ise 1sı değişim yüzey alanıdır. Yüksek 1sı değişim yüzey alanı daha fazla 1sı değişim potansiyeli sağlamaktadır. Bununla birlikte uygun pompalama gücünün hesaplanması için 1sı değiştirici boru hattı üzerinde oluşan basınç kayıpları da bilinmelidir. Basınç kayıpları belki kurulum alan kısıtlaması olmayan uygulamalar için önemli olmayabilir ama kısıtlı alan içerisinde kurulması planlanan sistemlerde kullanılan sarmal tip 1sı değiştirici tasarımlarında enerji verimliliğini etkileyen baş etken basınç kayıplarıdır [11-15].

İște bu çalışmada yatay-sarmal tip toprak 1sı değiştiricilerin tasarımlarında ve uygulamalarında bilgisayar destekli simülasyonların kullanımlarının geliştirilmesi ve yaygınlaştırılması amacıyla 30 $\mathrm{m}^{2}$ lik bir bahçe alanı içerisine kurulması tasarlanan yedi farklı ısı değiştirici arasından en yüksek enerji verimli olanının simülasyonlar aracıllı̆g ile bulunması hedeflenmiştir.

\section{Materyal ve Metot}

\subsection{Modellerin geometrik tasarımları}

Tasarlanan yedi farklı yatay-sarmal tip toprak 1sı değiştiricilerin, apartman bahçesi gibi, alan kısıtlaması olan bölgelerde evsel kullanım (domestic use) için kullanılabilmeleri düşünülerek yaklaşık $30 \mathrm{~m}^{2}$ 'lik $(6 \mathrm{mx} 5 \mathrm{~m})$ kısıtlı bir toprak alanı üzerine kurulumları planlanmıştır (Şekil 1). Böyle bir seçim yapılmasının nedeni ise bu tür sistemlerin yaygın kullanımlarında alan kısıtlamasına rağmen kullanılabilirliklerinin ortaya konulmak istenmesidir. Burada önemle belirtmek gerekir ki geometriler tasarlanırken daha önceden yapılmış bazı çalışmalardan yararlanılmış olsa da tüm tasarımlarda özgün değişiklikler gerçekleştirilmiştir (Şekil 1). Böyle bir alan için kullanılması en verimli geometrik tasarımı bulmak için kullanılan bütün parametreler daha önce yapılmış çalışmalar tarafından önerilen değerlerin içerisinde kalması sağlanmıştır $[7,8,10,11]$. Slinky olarak tabir edilen ve içiçe geçen dairesel borulardan oluşan tasarıma alan kısıtlaması sebebi ile yer verilmemiştir. Çünkü bu tür tasarımlar için önerilen hendek uzunluğu 10 metreden az olmamakta ve döngü çapların da 0,8 metreden az olmaması önerildiği için tasarımlara eklenmemiştir $[8,14,16,18]$.

Tasarımlar yapılırken borular arasındaki mesafe 0,3 metre olacak şekilde ayarlanmıştır ki bu miktar topraktan verimli bir şekilde 1sı kazanımının gerçekleşmesini için diğer çalışmalar tarafından önerilen en küçük miktardır [7,8,10,11]. Tasarımlarda boru çapı 0,02 metre olarak alınmıştır [8,18]. 


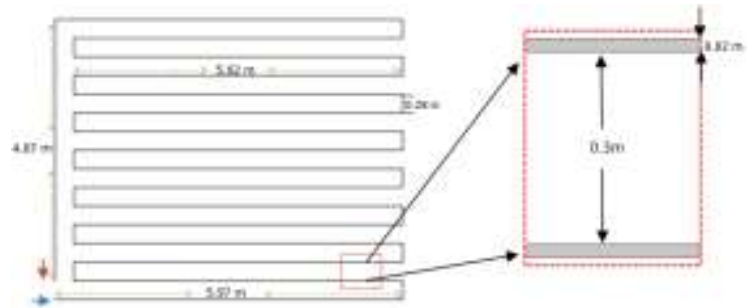

(a) Tasarım-1 [16]

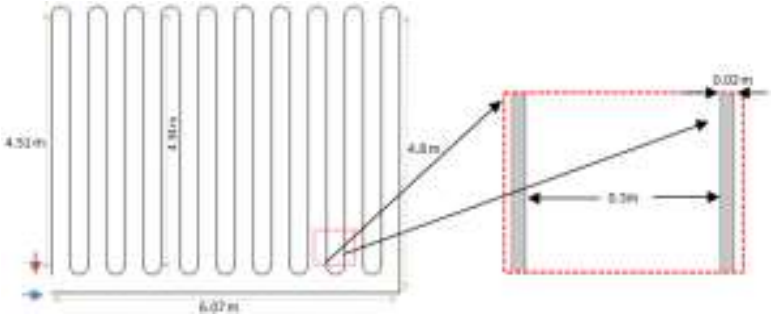

(c) Tasarım-3 [19]

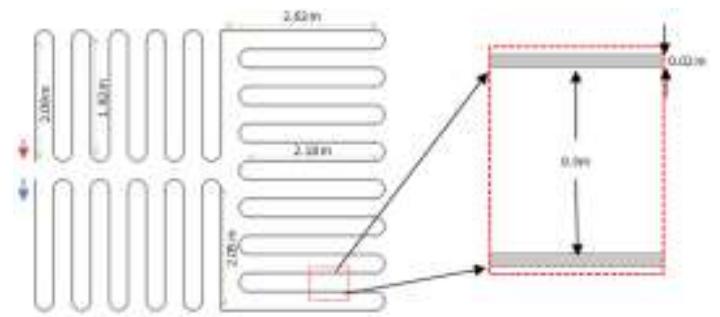

(e) Tasarım-5 [19]

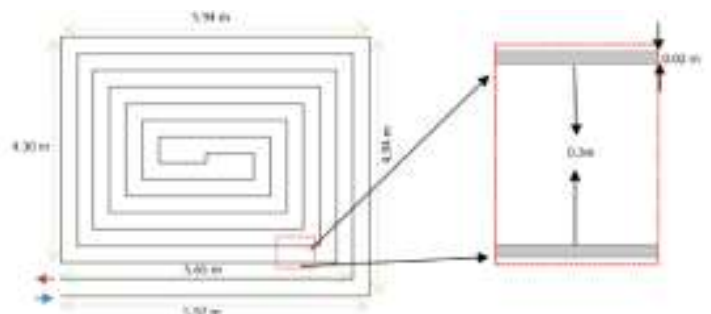

(b) Tasarım-2 [9]

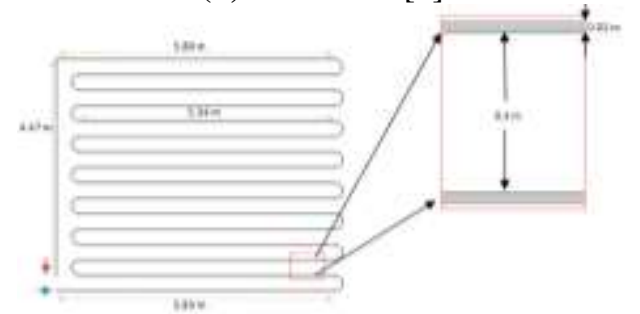

(d) Tasarım-4 [19]

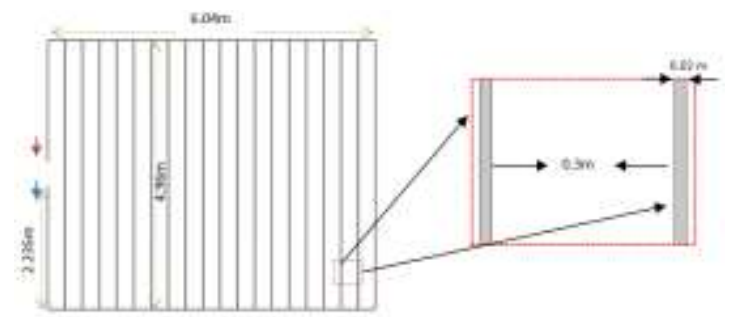

(f) Tasarım-6 [20]

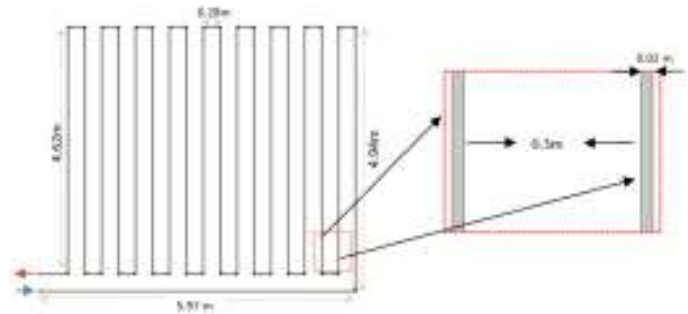

(g) Tasarım-7 [16]

Şekil 1. Çalışmada kullanılan model tasarımları

\subsection{Sayısal modelin oluşturulması}

Tasarımlarda akışkanın (Tablo 1) basınç dağılımını hesaplamak için Navier-Stokes ve süreklilik denklemleri (Eşitlik 1 ve 2) iki boyutlu olarak COMSOL (ver.5.2) programı yardımı ile çözülmüştür.

Tablo 1. Kullanılan akışkanın termal özellikleri [21]

\begin{tabular}{ccccc}
\hline Materyal & $\begin{array}{c}\text { Yoğunluk } \\
\left(\mathrm{kg} . \mathrm{m}^{-3}\right)\end{array}$ & $\begin{array}{c}\text { Özgül Is1 } \\
\left(\mathrm{J}_{\mathrm{kgg}}^{-1} \mathrm{~K}^{-1}\right)\end{array}$ & $\begin{array}{c}\text { Is1l iletkenlik } \\
\left(\mathrm{W} . \mathrm{m}^{-1} \mathrm{~K}^{-1}\right)\end{array}$ & Dinamik vizkozite (Pa.s) \\
\hline $\mathrm{Su}\left(20^{\circ} \mathrm{C}\right)$ & 998 & 4182 & 0,598 & $1,002 \times 10^{-3}$ \\
\hline
\end{tabular}

Akış rejimi geçiş bölgesinde (transitional flow) kabul edilmiştir. Isı değiştiricilerin girişine sınır koşulu olarak basınç tanımlanmıştır. Basınç olarak tanımlanmasının sebebi basınç kaybının doğrudan gözlemlenmek istenmesidir. Girişteki akış basıncı (gauge-çalışma basınc1) ise $100 \mathrm{kPa}$ olarak kabul edilmiştir. Bu yüksek değerin seçilmesinin temel nedeni akış sırasında gerçekleşecek olan kayıpların anlaşılır bir şekilde görülmesidir. Çünkü denenen daha düşük giriş basınçlarında anlamlı sonuçlar elde edilememiştir. Boruların iç cidarlarına kaymama (no-slip, $\mathrm{u}=0$ ) sınır koşulu tanımlanmıştır (Tablo 2). 


$$
\begin{aligned}
& \rho\left(\frac{\partial \vec{u}}{\partial t}+\vec{u} \cdot \nabla \vec{u}\right)=-\nabla P+\mu \nabla^{2} \vec{u} \\
& \nabla \cdot \vec{u}=0
\end{aligned}
$$

Tablo 2. Çalışmada tanımlanan sınır koşullar

\begin{tabular}{ll}
\hline Boyut (Dimension) & Sınır Şartları (Boundary Conditions) \\
\hline \multirow{2}{*}{ 2-D (x, y) } & - Giriş Basıncı (Pressure) $=100 \mathrm{kPa}$ \\
& - Çıkış Basıncı (Pressure) $=0 \mathrm{kPa}$ \\
& - Cidar kaymama koşulu (No-Slip) \\
\hline
\end{tabular}

\subsection{A $\breve{g}$ (mesh) yapısının belirlenmesi}

Başlangıçta çözümde yakınsamayı elde etmek için Şekil 2'de görüldüğü gibi iki farklı ağ (mesh) yapısı sisteme tanımlanarak farklı yapıdaki ağlarında çözüme etkisi incelenmiştir. Çözümü kolaylaştırmak için önce düz boru bölgelerine tek düze (uniform) dikdörtgensel, akışın daha karmaşık olduğu tahmin edilen dirseklere ise üçgensel ağ tanımlandı (Şekil 2.a). Bu sayede COMSOL programının çözümü daha kolay yakınsaması ve bilgisayarın daha kısa sürede çözüm üretmesi planlandı ama en iyi ağ sisteminin tamamen üçgensel ağ elemanlarından oluşturulması ile elde edileceği görüldü. Sonuçta bütün tasarımlara yaklaşık olarak aynı eleman sayısındaki üçgensel ağ yapısı atandı (Şekil 2.b). Ağ yapısından bağımsız sonuçlar ve hesaplama kolaylı̆̆ı açısından en uygun (optimum) ağ eleman sayısı 200 bin civarında bulunmuştur. Hesaplamalar dört adet fiziksel, dört adet sanal işlemciye sahip intel-i7 işlemcili ve 16 GB RAM belleğe sahip bilgisayar ile yapılmıştır. En uygun ağ yapısının saptanması yaklaşık bir aylık bir çalışma sonucu bulunduktan sonra her bir tasarım için hesaplar 1 ile 5 dakika arasında vakit almıştır.

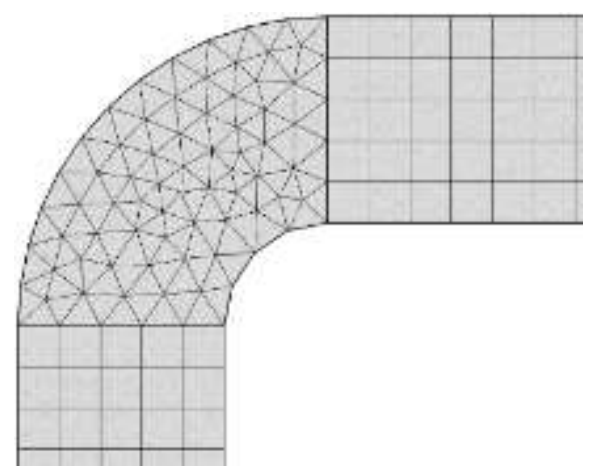

(a)

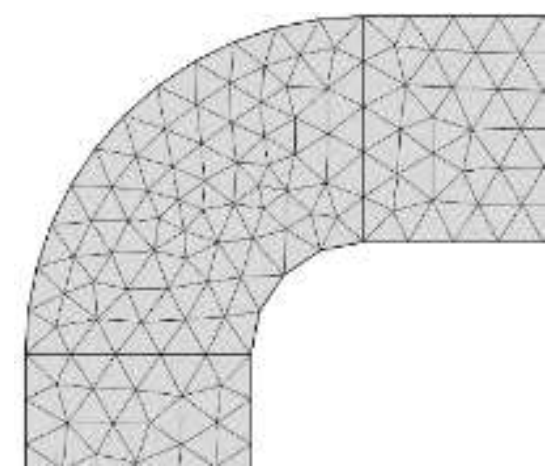

(b)

Şekil 2. Denenen ă̆ (mesh) yapıları

\section{Bulgular ve Tartışma}

Tasarımlara ait ısı değişim yüzey alanları teorik olarak, tasarımlarda meydana gelen basınç kayıpları da COMSOL programı yardımı ile sayısal (numerical) olarak hesaplanmıştır. Sonuçları daha anlamlı olarak karşılaştırabilmek için "enerji kazanım oranı (EKO)" olarak tabir edilen bir değer kullanılmıştır. Bu oran (EKO) 1sı değişim yüzey alanlarının basınç kayıplarına oranını temsil etmektedir (Eşitlik 3).

$$
E K O=\frac{\text { Isı Değişim Yüzey Alanı }\left(m^{2}\right)}{\text { Basınç Kaybı }(k P a)}
$$

\subsection{Isı değişim yüzey alanları açısından değerlendirme}

Isı değişim yüzey alanının artması ile 1sı kazanımı da artar. Buna bağlı olarak, hesaplanan 1sı değişim yüzey alanları en yüksekten küçüğe sıralandığında Tasarım-6, Tasarım-2, Tasarım-3, Tasarım-1, Tasarım-4, Tasarım-5 ve Tasarım-7 olduğu görülmüştür (Tablo 3). 
Tablo 3. Sonuçlar

\begin{tabular}{lccccc}
\hline & $\begin{array}{c}\text { Isı Değişim } \\
\text { Yüzey Alanı }\left(\mathrm{m}^{2}\right)\end{array}$ & $\begin{array}{c}\text { Basınç } \\
\text { Kaybı }(\mathrm{kPa})\end{array}$ & $\begin{array}{c}\text { Enerji Kazanım Oranı } \\
\left(\mathrm{m}^{2} / \mathrm{kPa}\right)\end{array}$ & $\begin{array}{c}\text { Toplam Boru } \\
\text { Uzunlukları }(\mathrm{m})\end{array}$ & $\begin{array}{c}\text { Dirsek } \\
\text { Sayıs1 }\end{array}$ \\
\hline Tasarım-1 & 6,2988 & 98,4740 & 0,0640 & 100,25 & 31 \\
Tasarım-2 & 6,4909 & 98,2788 & 0,0660 & 103,30 & 32 \\
Tasarım-3 & 6,4748 & 98,1746 & 0,0660 & 103,05 & 20 \\
Tasarım-4 & 6,1827 & 97,6076 & 0,0633 & 98,40 & 16 \\
Tasarım-5 & 6,1436 & 99,0874 & 0,0620 & 97,78 & 37 \\
Tasarım-6 & 6,9681 & 88,9790 & 0,0783 & 110,90 & 4 \\
Tasarım-7 & 6,1154 & 98,9376 & 0,0618 & 97,33 & 36 \\
\hline
\end{tabular}

\subsection{Basınç kayıpları açısından değerlendirme}

Bilindiği üzere yerel basınç kayıplarını etkileyen önemli parametrelerden biri dirsek sayısıdır. $\mathrm{Bu}$ yüzden de en düşük basınç kaybını beklendiği gibi en az dirsek sayısına sahip olan Tasarım-6 vermiştir (Şekil 3). Burada şunu belirtmek gerekir ki birbirine paralel olan boruların ana giriş dağıtım borusuna ve çıkış borusuna bağlantıları $T$ bağlantı (tee joint) olarak adlandırılır ve dirseğe göre basınç kayıpları daha azdır. Bu sebeple Tasarım-6'nın dört adet dirseğe sahip olduğu söylenebilir.

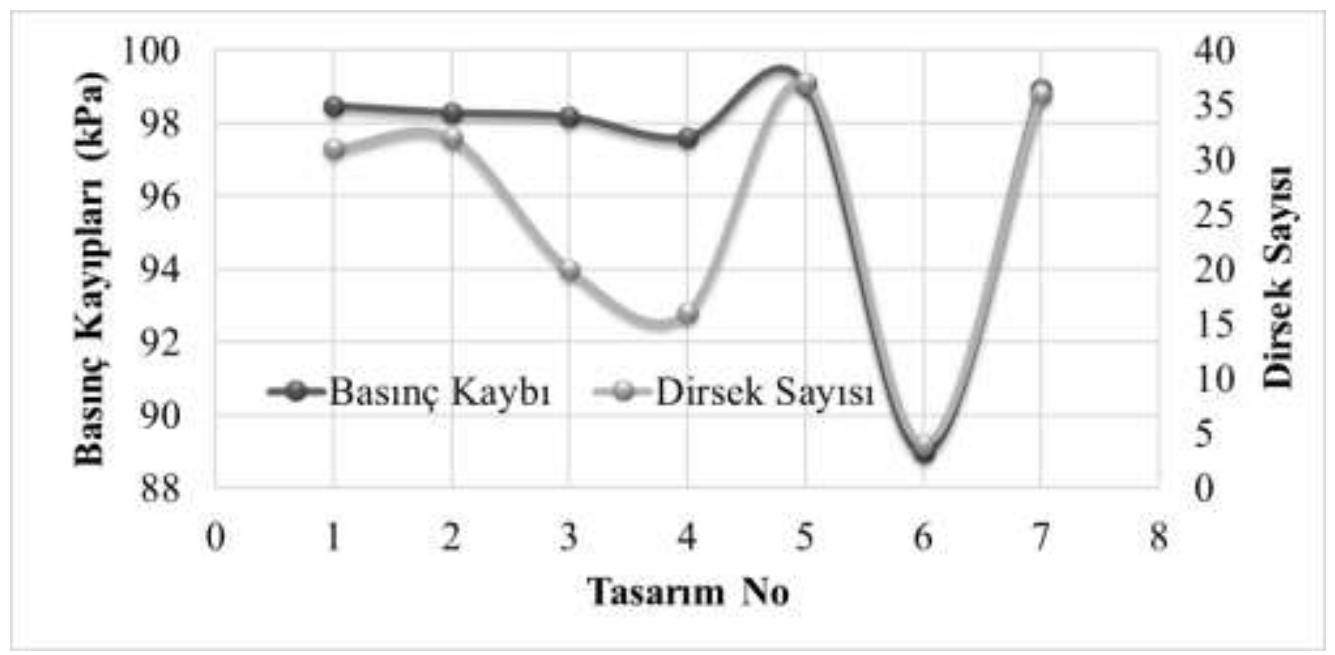

Şekil 3. Dirsek sayısı ile basınç kayıplarının karşılaş̧ırılması

Bunun yanında en fazla dirsek sayısına sahip Tasarım-5 ise en yüksek basınç kaybı gerçekleşmiştir. Ancak basınç kayıplarının sadece dirsek sayısından etkilenmediğini söylemek için Tasarım-1 ve Tasarım-2'ye bakılabilir. Bu ikisi karşılaştırıldığında, Tasarım-2'nin toplam boru uzunluğunun daha fazla olması (yaklaşı olarak 3,15 metre daha uzun) ve kullanılan dirsek sayısının 1 adet fazla olmasına rağmen basınç kaybı Tasarım-1'e kıyasla daha azdır (Çizelge 3 ve Şekil 3). Bu iki tasarım arasındaki farkın Tasarım-2'deki dirseklerin daha kavisli (yumuşak kenarlı) olmasından kaynaklandığ tahmin edilmektedir.

\subsection{Enerji kazanım oranı açısından değerlendirme}

Tasarımların enerji verimliliği açısından (Şekil 4) karşılaştııılmalarında Enerji Kazanım Oranı olarak tabir edilen değer kullanıldı (Eşitlik 3) ve en verimli sonucu Tasarım-6 $\left(0.0783 \mathrm{~m}^{2} \cdot \mathrm{kPa}^{-1}\right)$ gösterdiği bulundu. 


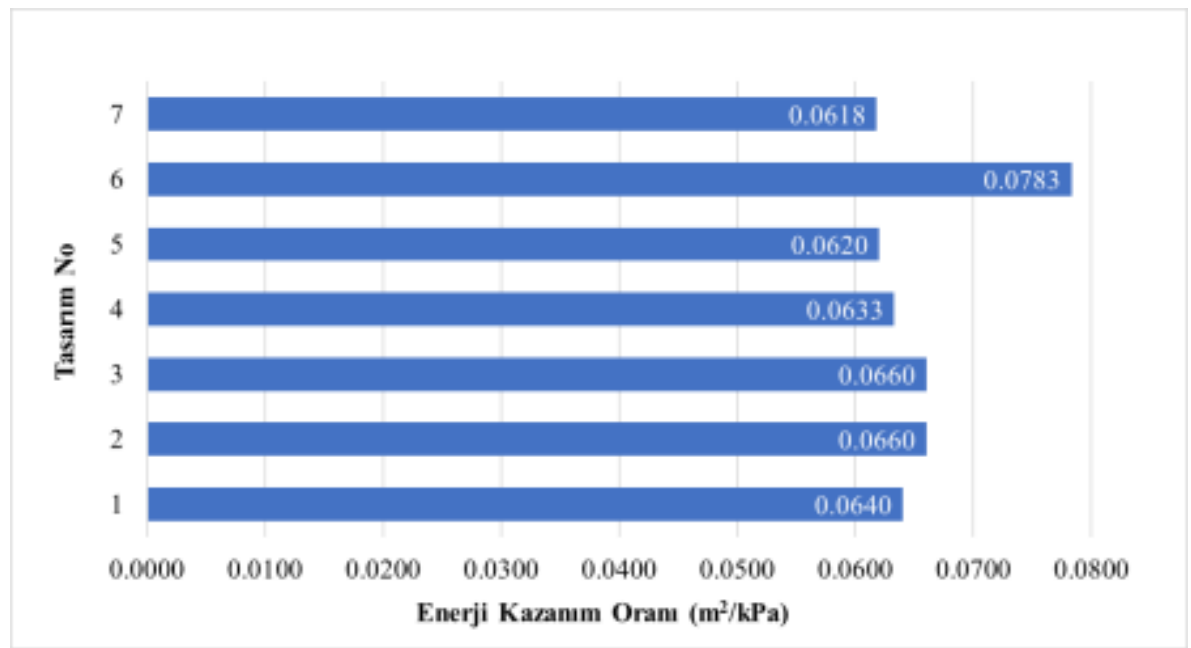

Şekil 4. Tasarımların enerji kazanım oranları (EKO)

Tasarımlar arasında 1sı değişim yüzey alanı bakımdan en yüksek değere sahip olan Tasarım-6, basınç dağılımları incelendiğinde de en düzgün akışkan dağılımına sahip olmasıyla diğer tasarımlara göre daha verimli çalışacağı tahmin edilmektedir (Şekil 5).

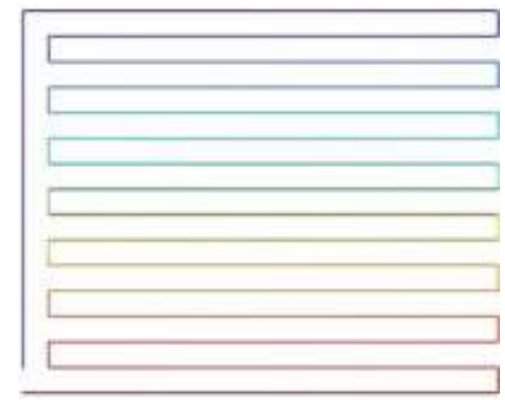

(a) Tasarım-1

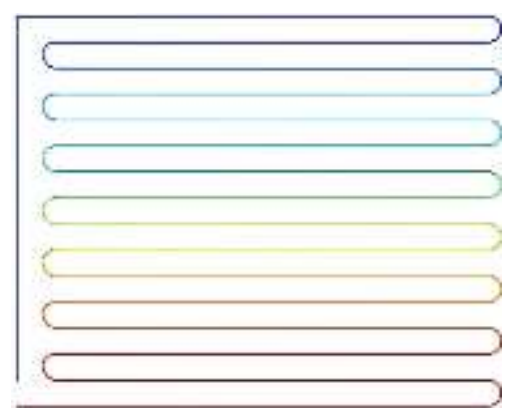

(d) Tasarım-4

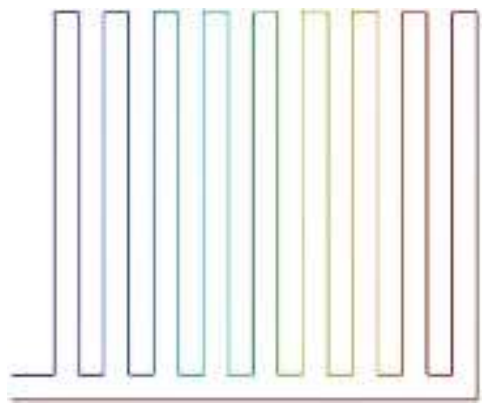

(g) Tasarım-7

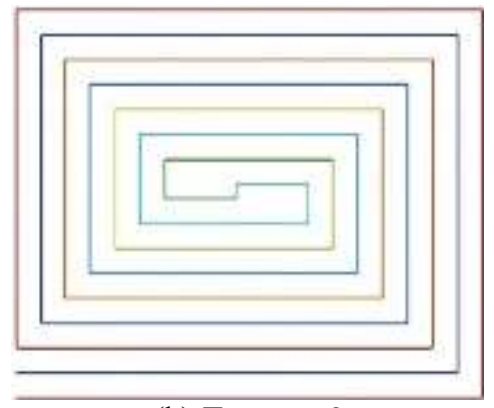

(b) Tasarım-2

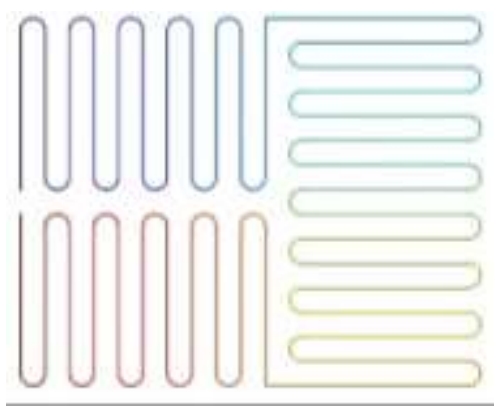

(e) Tasarım-5

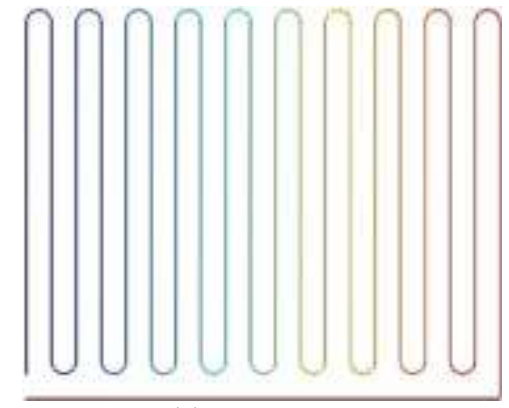

(c) Tasarım-3

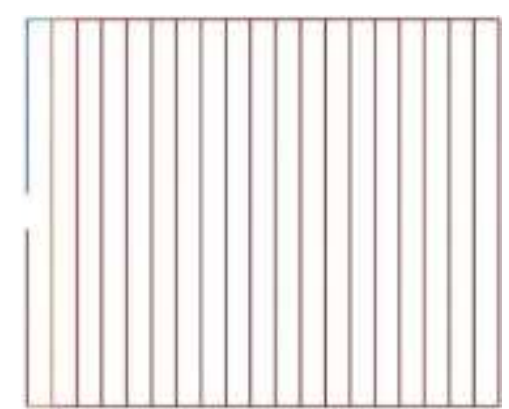

(f) Tasarım-6

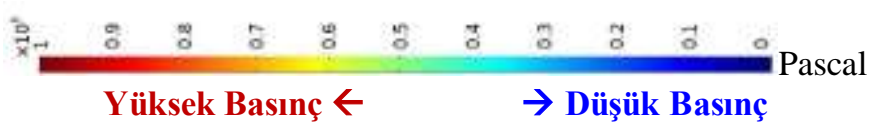

Şekil 5. Sayısal olarak hesaplanan basınç dağılımları 


\subsection{Benzer tasarımların karşılaştırılması}

Isı değiştirici tasarımları yapılırken belirlenmiş olan $30 \mathrm{~m}^{2}$ 'lik $(6 \mathrm{~m} \times 5 \mathrm{~m})$ kurulum alanının dışına çıkılmamasına büyük önem gösterilmiştir. Modellere bakıldığında Tasarım-1 ile Tasarım-7 ve Tasarım3 ile Tasarım-4 birbirlerine benzemektedir (Şekil 5). Ancak basınç kayıpları incelendiğinde tasarımlar arasındaki farklar görülmüştür. Tasarım-1 ve Tasarım-4'te 1sı değiştirici boruları 6 metrelik genişliğe paralel yerleştirilirken, Tasarım-3 ve Tasarım-7 bu genişliğe dikey (y-ekseni) olarak yerleştirilmiştir. Boruları yatay (x-ekseni) olarak yerleştirmek boruların daha uzun olmasını sağlayarak daha az dirsek sayısına ihtiyaç duyulmasına olanak vermiştir (Çizelge 3).

\section{Sonuç ve Öneriler}

Çalışmada en verimli sistemlerin Tasarım-6, Tasarım-2 ve Tasarım-3 oldukları bulunmuştur.

Her ne kadar diğer tasarımlara göre Tasarım-6 en enerji verimli gözükse de işletim ve bakım açısından bir değerlendirilme yapılırsa Tasarım-2 ve Tasarım-3 yek pare (intact body) olarak kullanılabileceklerken Tasarım-6'nın çok fazla bağlantı elemanı içermesinden dolayı (sızdırma problemi gibi) pratik kullanımının riskli olduğu düşünülmektedir.

Çalışmada tasarımların karşılaştııılması iki boyutlu benzetimler (simulation) üzerinden yapılmış ve iki boyutlu yaklaşımın yeterli olabileceğine dair güven verici sonuçlar elde edilmiştir. Fakat yine de tasarımların üç boyutlu olarak incelenmesi ve bu çalışma ile kıyaslanması gerekmektedir. Bu sayede hassas ve yoğun ağ yapısı oluşturulması daha kolay olan iki boyutlu simülasyonların kullanım güvenilirlikleri de net olarak ortaya konmuş olabilecektir.

\section{Yazarların Katkısı}

Yazarlar makaleye eşit oranda katkı sağlamıştır.

\section{Çıkar Çatışması Beyanı}

Yazarlar arasında herhangi bir çıkar çatışması bulunmamaktadır.

\section{Araştırma ve Yayın Etiği Beyanı}

Yapılan çalışmada araştırma ve yayın etiğine uyulmuştur.

\section{Kaynaklar (Eklenen kaynaklar gösterildi ve kaynakların atıf sırası değiştirildi)}

[1] Doğan H., Yılankırkan N. 2015. Türkiye'nin Enerji Verimliliği Potansiyeli ve Projeksiyonu. Gazi Üniversitesi Fen Bilimleri Dergisi Part C: Tasarım ve Teknoloji, 3 (1): 375-384.

[2] Kesicki F., Yanagisawa A. 2015. Modelling the Potential for Industrial Energy Efficiency in IEA's World Energy Outlook. Energy Efficiency, 8 (1): 155-169.

[3] Economidou M., Todeschi V., Bertoldi P., Agostino D., Zangheri P., Castellazzi L. 2020. Review of 50 years of EU Energy Efficiency Policies for Buildings. Energy and Buildings, 225: 110322.

[4] Staffell I., Brett D., Brandon N., Hawkes A. 2012. A Review of Domestic Heat Pumps. Energy \& Environmental Science, 5 (11): 9291-9306.

[5] Gan G. 2018. Dynamic Thermal Performance of Horizontal Ground Source Heat Pumps. The Impact of Coupled Heat and Moisture Transfer. Energy, 152: 877-887.

[6] Liu X., Lu S., Hughes P., Cai Z. 2015. A Comparative Study of the Status of GSHP Applications in the United States and China. Renewable and Sustainable Energy Reviews, 48: 558-570.

[7] Sarbu I., Sebarchievici C. 2014. General Review of Ground-Source Heat Pump Systems for Heating and Cooling of Buildings. Energy and Buildings, 70: 441-454.

[8] Banks D. 2012. An Introduction to Thermogeology: Ground Source Heating and Cooling. Wiley-Blackwell Baskı No:2, United Kingdom. 
[9] Karakoyun Y., Açıkgöz Ö., Dalkılıç A.S., Yumurtacı Z. 2020. An Experimental Investigation on Radiant Floor Heating Systems at Various Operating Conditions. Journal of Thermal Engineering, 6 (5): 751-771.

[10] Esen H., İnall1 M., Esen M., 2007. Numerical and Experimental Analysis of a Horizontal Ground-Coupled Heat Pump System. Building and Environment, 42: 1126-1134.

[11] Hepbaşlı A., Hancıoğlu E. 2001. Toprak Kaynaklı (Jeotermal) Isı Pompalarının Tasarımı, Testi ve Fizibilitesi. V. Ulusal Tesisat Mühendisliği Kongresi ve Sergisi, 3-6 Ekim 2001, İzmir.

[12] Soğancı S., Tutkun M.O. 2019. Akış Analizleri (CFD) ve Mühendislik Süreçlerine Katkıları. 14. Ulusal Tesisat Mühendisliği Kongresi, 17-20 Nisan 2019, İzmir.

[13] Bhutta M.M., Hayat N., Bashir M.H., Khan A.R., Khan S., Ahmad K.N. 2012. CFD Applications in Various Heat Exchangers Design: A Review. Applied Thermal Engineering, 32: $1-12$.

[14] Yoon S., Kim M.J., Jeon J.S., Jung Y.B. 2021. Significance Evaluation of Performance Factors on Horizontal Spiral-Coil Ground Heat Exchangers. Journal of Building Engineering, 35: 102044.

[15] Pu L., Xu L., Qi D., Li Y., 2019. A Novel Tree-Shaped Ground Heat Exchanger for GSHPs in Severely Cold Regions. Applied Thermal Engineering, 146: 278-287.

[16] Fujii H., Nishi K., Komaniwa Y., Chou N. 2012. Numerical Modeling of Slinky-Coil Horizontal Ground Heat Exchangers. Geothermics, 41: 55- 62.

[17] Xiong Z., Fisher D. E., Spitler J.D. 2015. Development and Validation of a Slinky ${ }^{\mathrm{TM}}$ Ground Heat Exchanger Model. Applied Energy, 141:57-69.

[18] Chong C.S.A., Gan G., Verhoef A., Garcia G.R., Vidale P.L. 2003. Simulation of Thermal Performance of Horizontal Slinky-Loop Heat Exchangers for Ground Source Heat Pumps. Applied Energy, 104:603-610.

[19] Mirzanamadi R., Hagentoft C.E., Johansson P. 2020. Coupling a Hydronic Heating Pavement to a Horizontal Ground Heat Exchanger for Harvesting Solar Energy and Heating Road Surfaces. Renewable Energy, 147: 447-463.

[20] Anonim, 2010. Geothermal Communities, https://geothermalcommunities. eu/assets/presentation/5.Course_GT.pdf (Erişim Tarihi: 18.03.2021)

[21] Çengel Y., Ghajar A. 2019. Isı ve Kütle Transferi Esasları ve Uygulamaları. Palme Yayınevi Bask1 No:4, s. 878, Ankara-Türkiye. 